\title{
Component processes of early reading, spelling, and narrative writing skills in Turkish: a longitudinal study
}

Article

Accepted Version

Babayiğit, S. and Stainthorp, R. W. (2010) Component processes of early reading, spelling, and narrative writing skills in Turkish: a longitudinal study. Reading and writing: an interdisciplinary journal, 23 (5). pp. 539-568. ISSN 0922-4777 doi: https://doi.org/10.1007/s11145-009-9173-y Available at https://centaur.reading.ac.uk/15720/

It is advisable to refer to the publisher's version if you intend to cite from the work. See Guidance on citing.

To link to this article DOI: http://dx.doi.org/10.1007/s11145-009-9173-y

Publisher: Springer

Publisher statement: The original publication is available at www.springerlink.com

All outputs in CentAUR are protected by Intellectual Property Rights law, including copyright law. Copyright and IPR is retained by the creators or other copyright holders. Terms and conditions for use of this material are defined in the End User Agreement.

www.reading.ac.uk/centaur 
Central Archive at the University of Reading

Reading's research outputs online 


\title{
Component Processes of Early Reading, Spelling,
}

\section{and Narrative Writing Skills in Turkish: A Longitudinal}

\section{Study}

\author{
Selma Babayiğit ${ }^{1}$ \& Rhona Stainthorp ${ }^{2}$ \\ ${ }^{1}$ University of York, University of the West of England (Bristol) \& ${ }^{2}$ University of Reading
}

\section{S. Babayiğit}

School of Psychology, University of the West of England(Bristol), Coldharbour Lane, Bristol, BS16 1QY, UK.

Email: selma.babayigit@uwe.ac.uk.

\section{R. Stainthorp}

University of Reading, $U K$.

Article Note. All the data for this study were collected as part of Dr. Babayiğit's doctoral research at the Institute of Education, University of London, UK.

Acknowledgements

We would like to thank the participating teachers, parents, and children from the 23 Nisan Primary School and Karaoğlanoğlu Primary School for their willing participation and cooperation. Many thanks also go to Mrs. Arzu Cankoy and Mrs. Ülfet Canseç for their help with the scoring of the written compositions of the children.

Preparation of this paper was supported by a Postdoctoral Fellowship Award given by the Economic and Social Research Council. Finally, we would like to thank Prof. Charles Hulme for his suggestions on an earlier draft of this paper. 


\begin{abstract}
The study examined, i) the role of phonological, grammatical, and rapid automatized naming (RAN) skills in reading and spelling development; and ii) the component processes of early narrative writing skills. Fifty seven Turkish-speaking children were followed from Grade 1 to Grade 2. RAN was the most powerful longitudinal predictor of reading speed and its effect was evident even when previous reading skills were taken into account. Broadly, the phonological and grammatical skills made reliable contributions to spelling performance but their effects were completely mediated by previous spelling skills. Different aspects of the narrative writing skills were related to different processing skills. While handwriting speed predicted writing fluency, spelling accuracy predicted spelling error rate. Vocabulary and working memory were the only reliable predictors of the quality of compositioncontent. The overall model, however, failed to explain any reliable variance in the structural quality of the compositions.
\end{abstract}

Key words: reading, narrative writing, grammatical awareness, phonological awareness, RAN, spelling 


\section{Component Processes of Early Reading, Spelling, and Narrative Writing Skills in Turkish: A longitudinal Study}

There is now a substantial body of research into reading and spelling in consistent alphabetic writing systems with simple letter - sound relationships such as German, Finnish, and Turkish (see Joshi \& Aaron, 2006). So far, the primary focus of these studies has been the role of speech analysis (phonological awareness) and naming speed skills (RAN) in literacy development. Very few studies have examined the role of grammatical skills alongside these widely researched processing skills (e.g., Nikolopoulos, Goulandris, Hulme, \& Snowling, 2006). Broadly, grammatical awareness refers to the ability to process the morphological and syntactic structures of the spoken language and arguably, its role in literacy development is particularly relevant for consistent writing systems with rich agglutinative morphology such as Turkish and Finnish. In agglutinative languages, a series of suffixes are attached at the end of a noun or a verb and children are exposed to complex multimorphemic words from the very early stages of literacy development. Given the scarcity of research, it is not clear what role grammatical skills play in these consistent writing systems with rich inflectional morphology.

Likewise, our current understanding of the component processes of early narrative writing skills in consistent orthographies is very limited. Three central processing skills have been identified to underlie the early composition writing skills of children. These are the transcription (e.g., handwriting and spelling), verbal memory (e.g., short term memory and working memory), and text generation (e.g., oral language skills such as grammar and vocabulary) (Berninger, 1999; McCutchen, 2000). However, as the research evidence almost 
exclusively comes from studies conducted in English, we do not know the relative importance of these processing skills in consistent writing systems.

The present study seeks to address these issues and has two primary aims. First, to investigate the relative role of grammatical awareness, phonological awareness, and RAN in reading and spelling; second, to investigate the role of the three central component processes (i.e., transcription, text generation, and verbal memory) in early narrative writing skills in Turkish.

\section{Reading and spelling development in consistent writing systems: the role of phonological awareness, grammatical awareness, and RAN}

Phonological awareness is undoubtedly the most powerful predictor of reading skills in English (Muter, Hulme, Snowling, \& Stevenson, 2004; Wagner et al., 1997). The research evidence from consistent writing systems, however, has been contradictory. While some have found phonological skills to play a significant role in early reading skills (Dufva, Niemi, \& Voeten, 2001; Lyytinen et al., 2006; Patel, Snowling, \& de Jong, 2004; Silven, Poskiparta, Niemi, \& Voeten, 2007), others have found RAN to be a more reliable predictor of reading than phonological awareness (de Jong \& van der Leij, 1999; Landerl \& Wimmer, 2008; Wimmer \& Mayringer, 2002). Reading accuracy develops very fast in consistent orthographies and due to ceiling levels of performance, reading speed is used as an index of reading skills. However, phonological awareness is not as good predictor of reading speed as RAN (Savage \& Frederickson, 2005). Hence, the ease of development of reading accuracy, thereby reliance on reading speed as an index of reading skills might have contributed to these inconsistent findings.

At this point, it is important to highlight the distinction between reading and spelling. Spelling has been found to be a more sensitive index of phonological processing skills in English 
(Caravolas, Hulme, \& Snowling, 2001) and several studies in consistent writing systems such as Turkish, Dutch, and German have found phonological awareness to play a more central role in children's early spelling development than reading development (Babayiğit \& Stainthorp, 2007; Landerl \& Wimmer, 2008; van Bon \& van Leeuwe, 2003; Wimmer \& Mayringer, 2002). For instance, in a series of studies Wimmer and colleagues have found phonological skills to be predictive of spelling but not reading, and conversely, RAN was found to be the most powerful predictor of reading but not spelling (Landerl \& Wimmer, 2008; Wimmer \& Mayringer, 2002).

Thus far, very few studies in consistent writing systems have tested spelling alongside reading and clearly further research needs to clarify the observed divergence in the predictors of reading and spelling. Furthermore, as the primary research focus in this area tends to be phonological awareness and RAN, we do not know what role other language skills such as grammatical skills play in early reading and spelling development.

Grammatical awareness by definition entails semantic knowledge, awareness of morphophonemic structure of the words, and syntactic parsing. With respect to the relationship between reading and grammar, it is assumed that syntactic skills enable effective use of the context to facilitate word recognition (Bowey, 2005). The morphological skills are also proposed to enable effective morphological parsing of multimorpheme words, thereby facilitate recognition of these words (Bryant \& Nunes, 2004). However, the research evidence into the role of grammatical awareness in early reading skills tends to be highly inconsistent. While some have reported small but reliable relationships (Carlisle, 1995; Carlisle \& Nomanbhoy, 1993), others have found the effect of grammatical skills on reading to be either unreliable (Muter et al., 2004) or indirect through its relationship with the phonological skills (Nikolopoulos et al., 2006; Silven et al., 2007). We now turn to the link between grammatical skills and spelling. 
Most research into the grammar-spelling link has investigated the specific relationship between the ability to process certain morphosyntactic structures in oral language and the ability to spell these structures. So far, these studies have shown that the effect of grammatical skills on spelling is most evident in the processing of complex words that cannot be spelled accurately by applying the phoneme to grapheme correspondence rules. For example, the words that undergo phonological shift (e.g., <sign> and <signature>), contain irregular suffixes (eg., past tense suffix -ed is pronounced differently in <hunted $>$ and $<$ saved $>$ but spelled the same) or silent morphemes (e.g., plural -s in Spanish and French) (Defior, Alegria, Titos, \& Martos, 2007; Juul \& Elbro, 2004; Muter \& Snowling, 1997; Nunes, Bryant, \& Bindman, 1997; Senechal, Basque, \& Leclaire, 2006; Singson, Mahony, \& Mann, 2000; Titos, Defior, Alegria, \& Martos, 2003).

Hence, broadly there is the assumption that grammatical skills support reading and spelling of complex words where phonological strategy fails to provide an accurate answer. Given the evidence for this specific relationship, on the one hand the question arises as to whether grammatical skills play any role at all in languages with transparent morphology like Turkish and Finnish. After all, there is no need for morphosyntactic knowledge for accurate reading or spelling of words in these languages. On the other hand, given the central role of inflectional morphology in these languages, one would certainly expect grammatical skills to play a significant role in literacy development. In fact, one study has directly addressed this question with respect to spelling in Finnish and reported no specific relationships between the awareness of certain morphosyntactic structures and their accurate spelling (Lehtonen \& Bryant, 2005). However, in this study, morphological skills as a measure of general oral language skills were related to spelling. At this point, it is important to note that in a recent study in Dutch, the morphological skills failed to make any reliable unique contribution to spelling at Grade 1 after 
taking into account the variance accounted by the phonological skills (Rispen, McBride-Chang, \& Reitsma, 2008). However, Dutch is not an agglutinative language and given the scarcity of research it is not possible to ascertain to what extent language or methodological differences might have contributed to these inconsistent findings.

The interpretation of the findings in this area of research is further complicated by the fact that studies tend to focus on reading and spelling of single-morpheme words presented in isolation. Hence, we do not know whether these findings are also applicable to reading and spelling of inflected words in context. This issue is particularly relevant for agglutinative languages, in which long inflected words are the characteristic feature of the language.

\section{Composition writing}

Composition writing is clearly a complex process and taps a cascade of lower and higher level processing skills (Berninger, 1996; Flower \& Hayes, 1980; Graham \& Harris, 2000; Kellogg, 1996). Young children's early writings are characterised to be knowledge telling that is writing whatever a prompt brings to their mind and lacks higher levels of processing skills such as revision and planning (Bereiter, 1980). Therefore, the focus in this area of research has been on three developmental skills, namely transcription skills (i.e., spelling and handwriting fluency), text generation skills (e.g., transformation of ideas into oral language, which includes skills such as vocabulary and grammar) and working memory skills (Berninger, 1999). In this context, working memory is conceived as a limited information processing resource that enables the integration and coordination of the multiple components of writing. The three central component processes are in complex interaction with each other and seem to be differentially related to the different aspects of the writing skills (e.g., the length and quality of the writing) (Berninger et al., 
1992; Graham, 1999a; Graham, Berninger, Abbot, Abbot, \& Whitaker, 1997; Juel, 1988; Juel, Griffith, \& Gough, 1986; McCutchen, 2000; Swanson \& Berninger, 1996).

The lack of automaticity of the transcription skills is thought to interfere with the writing process, as the novice writer struggles to monitor the ongoing content generation process while at the same time s/he has to devote the attention to spelling. Hence, the lack of efficiency in the transcription process is considered to constrain content generation and writing fluency by increasing the processing load of the already limited working memory resources of the young children (Swanson \& Berninger, 1996). Consistent with these explanations, in a series of studies Berninger and colleagues have shown that the transcription skills and working memory skills are closely related to both writing fluency and quality among the elementary school children and as the transcription skills become more automated with increasing age, the effect of transcription skills on writing declined, while that of working memory remained relatively stable across time (Berninger et al., 1992). Several studies have also found handwriting fluency to play a more central role in writing than spelling accuracy further underscoring the importance of automaticity of transcription skills (Berninger et al., 1992; Graham et al., 1997).

The text generation process is directly linked to the components of oral language such as semantic knowledge, lexical retrieval, and grammatical processes (Berninger, 1996) and individual differences in language skills have been found to play a significant role in children's writing skills (Cragg \& Nation, 2006; Fey, Catts, Proctor-williams, Toblin, \& Zhang, 2004; Juel, 1988), Oral language is conceived to impact on text generation directly as well as indirectly through its facilitating effect on the working memory skills (see Kintsch, 1998). In line with this view, skilled writers have been found to perform better on working memory measures that 
require efficient activation, processing, and retrieval of lexical information from the long term memory (McCutchen, Covill, Hoyne, \& Mildes, 1994).

These findings, however, are not unequivocal. For instance, several studies failed to find any reliable relationship between children's grammatical skills (or oral language skills) and the structural quality of their written compositions (Berninger et al., 1992; Griffin, Hemphill, Camp, \& Wolf, 2004; Mackie \& Dockrell, 2004). Likewise, while some have reported unreliable relationships between writing fluency and writing quality (Fey et al., 2004), others have found strong and reliable relationships even among university students (Connelly, Dockrell, \& Barnett, 2005).

Research into writing among typically developing younger children is highly limited in English and even more so in consistent writing systems. In one such rare study in Finnish, it has been reported that spelling does not constrain text generation processes even during the early stages of literacy development (Maki, Voeten, Vauras, \& Poskiparta, 2001). In this study, spelling accuracy was marginally related to composition coherence from Grade 1 to Grade 2, and its relationship with the writing skills became unreliable thereafter (Grade 2 to Grade 3). This was explained in terms of the relative ease and speed of spelling development in Finnish (Maki et al., 2001). Unfortunately, automaticity of writing, oral language or memory skills was not assessed in this study.

Taken together, notwithstanding the ever increasing research evidence, there is still a great deal to be learnt about the component processes of reading, spelling, and writing in consistent orthographies. In this study, our overall goal was to address the following three main research questions within the context of Turkish. First, what are the relative role of phonological, grammatical, and RAN skills in early reading and spelling development? Second, do the relative 
contributions of these processing skills differ as a function of the type of literacy outcome measure (e.g., spelling versus reading or prose reading versus single word reading)? Third, what is the role of the three central component processes of composition writing in a consistent and highly inflected writing system?

\section{Method}

\section{Participants}

Fifty seven children (27 girls and 30 boys) were tested in the spring term of Grade 1 and then about 11 months later at Grade 2. The mean age at the beginning of the study was 6.6 years (range $=6.0$ to 7.1 years). All children spoke Turkish as their first language and came from two public schools in Kyrenia, Northern Cyprus. At beginning of the study, children had received about seven months of formal reading instruction involving a mixture of phonetic and whole word strategies. Nine children moved, thus could not be tested by the end of Grade 2 . Consent for testing was obtained from the school authorities, parents as well as children.

\section{Materials and procedures}

Children were tested individually at their schools. A large battery of tasks was implemented, only the relevant ones are reported here. Further details of the measures can be obtained from the first author. 
Measures implemented at Grade 1

Nonverbal IQ. Raven's Standardised Progressive Matrices (Raven, 1967) and Block design subset from the Turkish version of the WISC-R (Savasir \& Sahin, 1995) were used as a measure of nonverbal IQ.

Vocabulary. This was the vocabulary subset from the Turkish version of the WISC-R.

Short-Term Memory (STM). The forward digit- span subtest from the WISC-R was used to assess the verbal STM skills.

RAN. Children's naming times of letters, objects, and digits were recorded (adapted from Denckla \& Rudell, 1974). The objects were 5 single syllable common nouns [Fil (elephant), goz (eye), mum (candle), top (ball), kus (bird)], the letters were a, o, s, d, p, and the digits were 3, 5, $4,8,7$. The items were presented randomly as 5 rows of 10 items on each form. There was a task familiarisation trial at the beginning of each naming task to ensure that the items were accurately and consistently named. The final score was based on the average scores of the two trials for each naming task. There were very few errors and re-adjusted scores after taking into account the errors gave essentially the same results. Therefore, the original scores are reported. As the three RAN measures were highly related to each other ( $r$ 's ranged between $.72-.86, p<.001)$, it was appropriate to compute a composite mean z-score for this measure.

Working memory. This is based on the listening span task of Daneman and Carpenter (1980). Children listened to a series of simple declarative sentences that they had to verify by stating as true or false. Then, they had to recall verbatim the first word of each sentence in the order of presentation. In the English version of this task, often sentence- final words are asked to be recalled. However, as Turkish has Subject Object Verb word order, it was only possible to have nouns with no attached suffixes at the beginning of a sentence. Therefore, we have changed the 
format of the task and asked the children to recall the first word of the sentence [e.g., <Gül meyvedir> (Rose fruit-is), in which the to be recalled word was <Gül> (Rose)].

The sets of trials ranged between 2- sentence trials to 4-sentence trials. Children were given two sets of practice trails with feedback at the beginning of the test. There were three trials within each set and failure on all three or two trials within each set resulted with the termination of the test. One point of score was given for each correct trial.

Phonological awareness. The syllable and phoneme deletion tasks based on Bruce's (1964) word analyses test were used to assess phonological awareness skills. There were four practice trials with feedback before each task. After the deletion, the remaining part was always a nonword. Examples of these tasks are presented in Appendix A.

Syllable deletion. In this task, children were asked to say the remaining part of a word or nonword after deleting the target syllable spoken by the experimenter. The word length ranged between 2 to 3 syllables and the target to be omitted syllable was either in word initial, final or middle positions. There were a total of 21 trials with 12 real words and 9 nonwords.

Phoneme deletion. This was the same as the syllable deletion task except that the task was to omit a target phoneme from either a word or nonword. There were a total 18 items with 9 real words and 9 nonwords. One or two- syllable words were used.

Grammatical awareness. Two main tasks were developed to assess children's ability to process inflectional suffixes and analyse the syntactic structure of the spoken sentences (see Appendix A). All items were spoken by the experimenter with a natural prosody.

Morphological awareness. This task was designed to test children's ability to process inflectional morphology and was inspired from the earlier works of Berko (1958) and Durgunoglu (2003). The task composed of two parts. In part one, children made grammaticality 
judgment for the spoken sentences about a fictitious animal with a pseudonoun $\langle\mathrm{KEV}\rangle$. Nine sentences with correct and inaccurate forms were constructed making a total of 18 test trials, which were presented randomly. In the second part, after making the grammaticality judgment, the child was also asked to provide the correct form of any sentence indicated to be wrong. This time, another pseudonoun was presented as a reference to a different fictitious animal called $\langle\mathrm{BEV}\rangle$.There were 18 different sentences 9 of which were correct and the rest included inflectional suffixation errors. For the inaccurate items, children received a score only if they have made the appropriate correction. For some items, there were alternative correct answers. Any grammatically acceptable answer was considered accurate. Five practice trials with feedback preceded the test trials.

Syntactic awareness. This task simply involves re-ordering of the words in spoken sentences. There were 20 sentences with 3 to 4 words. The word order is relatively flexible in Turkish, but there are some constrains in such as the position of adjectives, adverbs, and question words (Ekmekçi, 1986). In this task, sentences with these structures were used in order to obtain a sensitive index of the ability to analyse the internal structure of the sentences. There were 5 practice trials with feedback prior to the test trials. Any grammatically acceptable answer received a score.

\section{Measures implemented at both Grade 1 and Grade 2}

Reading tasks. Three one minute word reading tasks and two text reading tasks were developed to assess the reading skills. In this way, we aimed to obtain a comprehensive assessment of reading skills.

One minute word reading. We have used three different one minute word reading tasks; one minute real word reading, one minute nonword reading, and one minute agglutinated word 
reading. The words were presented randomly on an A4 size card printed with 16 pixel size Century Gothic fonts. The task was to read accurately but as fast as possible until asked to stop. A stop watch was used to time the tasks and in each case the scoring was based on the number of accurately read words in one minute.

For the one minute real word reading task, 100 words with different levels of frequency were randomly presented. At the time of testing, there were no word frequency norms for children in Turkish, therefore we have used school books and a dictionary to select the words. For the nonword reading task, 90 nonwords were presented randomly. The nonwords were formed by changing several letters of the real words. Finally, for the agglutinated word reading task, we have constructed 72 inflected words. The number of attached suffixes ranged from 1 to 5. We have only used suffixes, as prefixes are observed on rare occasions in Turkish (Lewis, 1967). The syllable length of the words ranged between 1 to 7 in the word and nonword reading tasks, and 2 to 7 in the agglutinated word reading task.

Text reading. Two short narrative passages, one with 31 and the other with 30 words, were developed to assess prose reading skills. These tasks were also timed with a stop watch. Text reading accuracy score was based on the total reading accuracy across the two passages and the text reading speed was scored as the number of correct words read in one minute across the two passages.

Spelling. Spelling of single words (i.e., real words and nonwords) and sentences were assessed. Each item was read aloud twice.

Single word spelling. In this task, a list of 17 words was dictated of which 6 were words and 11 nonwords. The nonwords were constructed by changing several letters of real words. First 
a block of real words and then nonwords were presented. Children were informed about this transition point and have been told that some of the words will be strange.

Sentence spelling. In this task, 9 sentences were presented in the same way as described above. The sentences included 2 to 3 words with complex morphological structures.

Hand Writing Speed. This task was used as an index of automaticity (see Berninger et al., 1997; Graham, 1999b) or speed of translation of orthographic- phonological representations from memory into writing and involved writing repeatedly the first three days of the week from memory [i.e., Pazartesi ( Monday), Salı (Tuesday), Çarşamba (Wednesday)] until asked to stop. The total number of words written per minute was calculated.

\section{Measures implemented at Grade 2}

Composition writing. This task aimed to examine children's narrative writing skills and was scored in terms of spelling error rate, fluency (total number of words written per minute), content (story content and choice of vocabulary), and structure (e.g., number of clauses, sentence structure). Although composition structure and content are related dimensions, they also tap different developmental skills (see Berninger et al., 1992). Therefore, these two indices of composition quality were examined separately.

The task simply involved writing the events depicted in a series of eight pictures. The pictures showed a hiking trip during which a boy falls and hurts his foot. The children were told to study the pictures carefully and then when they were ready, to go back to the beginning and start writing the story. All 8 pictures were printed in order on an A4 size card and remained visible at the front while writing. The children were left to write their narrative essays at their own pace and their speed was recorded by a stop-watch. If they made any errors they were instructed to cross the word and rewrite next to it. 
Composition writing-fluency. Total number of words written per minute was used as an index of writing fluency.

Composition writing-spelling error rate. Children's spelling error rate was calculated by dividing the total number of spelling errors by the total number of written words.

Composition writing-content. The content of the written compositions was assessed in terms of the overall accuracy and clarity of the depiction of the events in the pictures and the appropriateness of the choice of vocabulary. The general content was scored on a scale of 1-5 ranging from 'very poor; mostly irrelevant information' to 'very good; accurate, vivid and highly detailed explanations of the depicted events'. Children's specificity in the choice of vocabulary was scored on a scale of 1-4 ranging from 'very poor, lacks precision and may be inappropriate' to 'very rich, appropriate and specific that conveys the meaning accurately'. The scoring of the vocabulary was based on the vocabulary subscale of the written expression part of the Wechsler Individual Achievement Text-Second UK Edition (WIAT II UK, 2005). Hence, the maximum possible score for the composition writing- content was 9 .

Composition writing-structure. The scoring procedure used to assess the organisational and structural quality of the writings was partly adapted from the written expression subtest of the WIAT- II and assessed such as the use of connectives and subordinate clauses (see Appendix B). The highest possible score for the composition writing-structure was 15 .

The written compositions were re-scored by two experienced primary school teachers. The average inter-rater reliability coefficients (Pearson Product Moment correlation coefficients) were relatively high (Table 1). 


\section{Results}

A summary of the descriptive statistics are presented on Table 1. With the exception of text reading accuracy, reliabilities of all the measures were acceptable (all above .70). The low test-retest reliability of the text reading accuracy is likely to be due the observed restricted variability on this task. As with the previous studies in Turkish (Öney \& Durgunoglu, 1997), we have also observed ceiling level of performance on the reading accuracy measure. For this reason, we have dropped text reading accuracy from the subsequent analyses.

\section{Correlational analyses}

The concurrent and longitudinal relationships between the measures are presented on Tables 2, 3, and 4. The following are the highlights of these analyses, which are specifically relevant to our research questions.

The different reading measures were highly related to each other ( $r$ 's ranged between .78-.92) at both testing occasions and their respective relationships with the predictor measures were also very similar (Tables $2 \& 3$ ). Although, phonological awareness, grammatical awareness, and STM correlated with the reading measures, clearly RAN was the most powerful longitudinal correlate of reading speed (Table 4). Likewise, the single word spelling and sentence spelling measures correlated strongly with each other at both testing occasions and both were related to the phonological and grammatical awareness measures.

In line with the previous research, we have also found the different components of composition writing to be differentially related to the predictor measures (Berninger, 1999). The composition writing fluency correlated very strongly with handwriting speed. Both word and sentence spelling accuracy measures were consistent and powerful correlates of the spelling error 
rate. The composition writing -content shared moderate to large variances with vocabulary and working memory. None of the Grade 1 measures were reliably related to the composition writing -structure. Finally, the composition writing-content and -structure measures correlated strongly with each other $(r=.59)$, suggesting that those who wrote compositions with better content also tended to produce grammatically better structured texts. It is also notable that the spelling error rate and writing fluency were not related to each other, and none of them were related to either the quality of the content or the organizational structure of the written compositions (Table 4).

\section{Stability of reading and spelling}

There was high stability between the reading speed measures from Grade 1 to Grade 2 ( $r$ 's ranged between $.63-.87$ ). There was also evidence for stability in spelling accuracy measures across the two consecutive testing occasions, albeit these tended to be less strong than reading $(r$ 's $=.54$ and .56$)$. These results are very similar to those reported in previous studies (e.g., Landerl \& Wimmer, 2008). Hence, although there was a sharp increase in children's overall reading speed and spelling accuracy from Grade 1 to Grade 2, those who read slowly were also slow readers one year later and a substantial proportion of children experienced continuing spelling difficulties. In this study, about $50 \%$ of the children with spelling accuracy scores below the mean at Grade 1 were still performing below the mean of their same age peers at Grade 2. This finding further underscores the difficulty of spelling even in a highly consistent spelling system (see Treiman \& Kessler, 2005). 


\section{Multiple regression analysis}

The measures we have used to assess each processing skill, namely nonverbal IQ (Raven's standard progressive matrices, block design), phonological awareness (syllable deletion and phoneme deletion), and grammatical awareness (morphological awareness and syntactic awareness) shared large variances with each other (see Table 2). For this reason, it was appropriate to form composite measures of these measures by calculating the mean standardised scores of the relevant component measures. This procedure not only serves to simplify the subsequent multiple regression analyses but also strengthens the reliability and validity of the measures used to assess each processing skill. The longitudinal correlations between these composite measures and the Grade 2 measures are presented on Table 4.

The diagnostic procedures for the multiple regression analyses (see Tabachnick \& Fidell, 2001) have revealed no multivariate outliers. Several measures were skewed. However, the transformation of the scores of these measures did not change the pattern of results. Hence, the following results are based on the nontransformed scores.

\section{Longitudinal predictors of reading and spelling}

Table 5 shows the Grade 1 predictors of reading at Grade 2. We excluded IQ, vocabulary, grammatical awareness, and working memory from the data analyses, as they were not related to either reading or spelling (see Table 4). The patterns of relationships were comparable across the different measures of reading skills suggesting uniformity in the underlying component processes of reading at this level of literacy development.

First, we conducted hierarchical multiple regression analyses of data and examined the unique contribution of each predictor measure after taken into account the variance accounted by 
previous reading skills ( i.e., the autoregressor) at Step 1. As the Model 1 (Table 5) clearly shows, after controlling for the autoregressor measure, only RAN made reliable unique contributions to reading measures. The only exception to this was text reading speed, whereby the effect of RAN was completely mediated by the powerful autoregressor. We repeated the same analysis and examined the predictive effects of Grade 1 measures after removing the powerful mediating effect of the autoregressor measure from the regression analysis. Model 2 (Table 5) shows that after controlling for verbal STM, phonological awareness made reliable albeit small contributions to word and agglutinated word reading but its effect on the nonword reading and text reading were negligible. Once again, the most powerful unique predictor of reading speed was RAN (see Table 5, Model 2).

Next, we conducted similar series of hierarchical regression analyses to examine the longitudinal predictors of spelling skills at Grade 2 (Table 6). Once again the variables unrelated to spelling skills, namely IQ, RAN, and working memory were excluded from the regression models (Table 4). The pattern of results tended to differ across the different measures of spelling skills. After controlling for the autoregressor, only grammatical awareness explained unique and reliable variance in word spelling (Table 6, Model 1). Although phonological awareness also explained $4 \%$ further variance, this was not statistically reliable. With respect to sentence spelling and spelling error rate, autoregressor was the only reliable predictor.

Once again, we re-run the analyses and explored these relationships after removing the powerful mediating effect of the autoregressor measure (Table 6, Model 2). Grammatical awareness explained reliable unique variances in both word and sentence spelling. Although phonological awareness also explained individual variances in word spelling skills, the effect 
size was small and became unreliable, once the variance accounted by grammatical skills was taken into account (Table 6, Model 2).

Interestingly, with the exception of the autoregressor (word spelling), none of the Grade 1 measures predicted spelling error rate in this study. This may partly suggest that other processes were influencing children's spelling performance whilst composing text. Children can clearly be more selective and choose words that they know and can spell well (see Mackie \& Dockrell, 2004). Or they may make spelling mistakes because of the limitations on the information processing or attentional resources. Writing involves spelling, while one is at the same time engaged in content generation, hence it is a multiple task condition that can naturally contribute to more spelling errors among younger children with limited information processing resources. Overall, these two main factors might have introduced much noise into the data contributing to the observed unreliable relationships. In fact, the concurrent relationship between the word spelling accuracy and spelling error rate was only moderate (44\% shared variance) at Grade 2 (Table 3), further suggesting that these two measures of spelling are not tapping the same processing skills.

\section{Predictors of Composition Writing-Spelling Error Rate and Composition Writing -}

\section{Fluency}

In the next series of multiple regression analyses, we have explored the role of word spelling accuracy and handwriting skills in the mechanics of writing (viz. composition writingspelling error rate and composition writing- fluency). We conducted both the concurrent and longitudinal analysis of data. The results were the same across the two testing periods (see Tables 7 and 8). Word spelling accuracy was the only reliable predictor of spelling error rate and handwriting speed was the only reliable predictor of writing fluency. The latter is in line with the 
findings of the previous reports (e.g., Berninger et al., 1992). It seems that spelling error rate and writing fluency are dissociable skills even during the early stages of writing development. This possibly reflects the consistency of the Turkish spelling system and will be further elaborated in the Discussion section.

\section{Predictors of composition writing quality: content and organisational structure}

Note that handwriting speed, IQ, and STM were not related to composition writing quality. In order to simplify the subsequent regression models, we included word spelling accuracy as an index of transcription skills, working memory as an index of verbal memory, and vocabulary and grammatical awareness as indices of oral language skills. Table 9 shows the results of the simultaneous multiple regression analysis. Vocabulary and working memory were the only reliable and unique predictor of composition writing-content (Table 9).

Although the observed effect of vocabulary was expected and is in line with the previous findings regarding the role of lexical knowledge in text generation, we were also interested to find out whether this relationship was evident after we remove the vocabulary choice scores (i.e., the choice of vocabulary) from the content scores. As the Table 10 clearly shows the overall effect size of vocabulary remained almost the same suggesting that the observed effect of vocabulary was not solely due to the vocabulary component of the content scores.

The redundant role of spelling accuracy and grammatical awareness in composition writing quality as well as the failure of the overall regression model to explain any reliable variance in composition writing-structure are surprising but have been reported before (Berninger et al., 1992; Griffin et al., 2004). We discuss the possible reasons for these puzzling findings in the next section. 


\section{Discussion}

In line with the previous research, the findings have revealed a clear dissociation between the predictors of reading and spelling. While RAN was a powerful and consistent longitudinal predictor of reading speed, there was evidence for stronger relationships between the oral language (i.e., grammatical and phonological awareness) and spelling accuracy skills. With respect to the composition writing skills, while word spelling accuracy predicted composition writing-spelling error rate, handwriting speed predicted composition writing-fluency. There was also a divergence in the predictors of the composition- content and composition-structure. Vocabulary and working memory made reliable contributions to the composition- content but the overall model failed to explain any reliable variance in the structural quality of the compositions. Finally, the findings suggested that the component processes of reading are comparable irrespective of the mode of assessment of reading skills but this may not apply to spelling, as we have observed differences across the different measures of spelling skills.

\section{Predictors of reading speed}

The observed powerful predictive relationship between the reading speed and RAN measures was expected and is certainly in line with the extant research evidence from the consistent writing systems (de Jong \& van der Leij, 1999; Landerl \& Wimmer, 2008; Wimmer \& Mayringer, 2002). Furthermore, this strong relationship remained irrespective of the word type (single-morpheme words or multi-morpheme words) or the mode of presentation of the words (in isolation or context). Our current understanding of why RAN is such as powerful predictor of reading speed is limited. Nonetheless, the observed divergence between the phonological awareness and RAN measures in this study further support the notion that RAN may index 
processes independent of phonology ( Powell, Stainthorp, Stuart, Garwood, \& Quinlan, 2007;

Wolf, Bowers, \& Biddle, 2000).

Phonological awareness was reliably related to reading skills at Grade 1 but its effect on the reading measures became redundant when RAN was taken into account. Given the observed ceiling levels of performance on the reading accuracy measures in this study, these results were not surprising and clearly echo those reported in other consistent orthographies (e.g., Landerl \& Wimmer, 2008).

In this study, we did not find any reliable effect of grammatical awareness on any reading skills. These results are in line with the findings of previous longitudinal studies in English and Finnish (e.g., Muter et al., 2004; Silven et al., 2007). It seems that during the early stages of reading development, grammatical skills do not play any reliable role in reading even in a highly inflected orthography and this seems to be the case irrespective of the word type or the mode of reading assessment. Further research needs to clarify to what extent these results reflect differences in orthographic consistency (e.g., relative ease of decoding in Turkish might render the role of morphosyntactic skills redundant) or the timing of the measurement. It is conceivable that the relationship between the grammatical awareness and reading skills may become stronger among older age groups when the grammatical awareness skills become more proficient and children are exposed to more complex texts (Carlisle, 2000; Singson et al., 2000).

\section{Predictors of spelling}

Although the autoregressor mediated the effects of phonological and grammatical awareness skills on spelling at Grade 2, clearly these two oral language skills were strongly related to spelling skills in this study, which is in accordance with the previous research findings (Babayiğit \& Stainthorp, 2007; Landerl \& Wimmer, 2008; Lehtonen \& Bryant, 2005). In this 
study, grammatical skills emerged as the most reliable unique predictor of sentence spelling at Grade 2. The closer relationship between the spelling of complex multi-morpheme words and grammatical skills is somewhat unsurprising but it is not clear why phonological awareness failed to predict sentence spelling. One possible reason may be the use of very complex multimorpheme words in the sentence spelling task that might have called for more morphosyntactic rather than phonological knowledge and strategies when children were trying to dictate these long words. Given the educational implications of these findings, further research needs to confirm these findings and also clarify to what extent the observed powerful link between grammar and spelling might have been shaped by the agglutinative nature of Turkish.

Finally, the overall findings from the different measures of spelling skills suggested that spelling is not as stable as reading and the mode of spelling assessment may influence the observed pattern of findings highlighting the importance of a comprehensive approach to spelling assessment (see Pattison \& Collier, 1992).

\section{Predictors of Composition writing}

Single word spelling accuracy was the only reliable predictor of spelling error rate in the narrative writing task. In line with the previous findings, we have also found the handwriting automaticity indexed by the handwriting speed measure to be a more powerful predictor of children's writing fluency than spelling accuracy (Berninger et al., 1992; Graham et al., 1997). Hence, the overall findings support the notion that children's early composition writing fluency can be constrained by handwriting automaticity. However, in this study we found no evidence for a limiting effect of these transcription skills on the writing quality. The transcription and quality indices were unrelated. Likewise, the mechanics of writing indexed by the spelling error rate and writing fluency were not related to the writing quality. These findings clearly echo those 
of Maki et al. who found unreliable relationships between spelling accuracy and writing quality and those of Fey et al. who reported unreliable relationships between writing fluency and writing quality. Once again, this early dissociation between the mechanical skills and writing quality may be due to the high levels of consistency of the Turkish spelling system. The observed inconsistent patterns of findings in the literature may also reflect differences in educational practices (see Barnett, Stainthorp, Henderson, \& Scheib, 2006). In Northern Cyprus, where this study had taken place, there is much emphasis on good handwriting skills and spelling takes up a large proportion of children's early literacy activities. This might have further facilitated the development of children's transcription skills so much so that it ceased to constrain the writing quality.

In this study, the individual differences in the semantic quality of the compositions were best predicted by the vocabulary and verbal working memory measures. Broadly, these findings fit well with the previous research that have outlined the oral language and/or working memory as the two central skills linked to young children's writing quality (Berninger, 1996; Fey et al., 2004). Although related, semantic and structural quality seem to tap different component processes, as none of the measures predicted the quality of composition structure. It is notable that Berninger et al. have also failed to find any reliable relationships between the oral language skills (i.e., verbal IQ, syntax) and the quality of the organizational structure of the compositions among similar age groups of children. One possible explanation for this finding might be the developmental lag between children's oral and written narrative skills. It is well documented that young children's oral narrative skills lags behind their written narratives, and with increasing age the quality of their written narrative skills become more commensurate with their oral narrative skills (Bereiter, 1980; Fey et al., 2004). The structural simplicity of early writings of 
young children is also reflected in the tendency to produce descriptive narratives with simple sentence structures (Bereiter, 1980). We have observed this profile of writing in this study as well where most children (89\%) used either none or only one linking expression. It follows that the quality of language structure of children's early written narratives might not capture individual differences in oral language skills. This might be one contributory factor to the observed dissociation between the oral language skills and the structural quality of the compositions. These findings suggest the importance of educational practices to help children to bridge the gap between their oral and written language skills.

\section{Conclusion}

The present study has made a contribution to this area of research by not only replicating the previous findings in relation to the central role of RAN in reading speed in a consistent orthography, but by also showing that these findings can be extended to a variety of reading outcome measures and word types. Most importantly, we have found that in addition to phonological awareness, grammatical skills also play a significant role in spelling development in a highly consistent spelling system with rich inflectional morphology. The findings from the multiple measures of spelling suggested that unlike reading, spelling processes of young children can be influenced by the mode of assessment, hence the importance of more comprehensive approach to the assessment of spelling skills. Finally, the findings underscored the need to differentiate across the different aspects of children's written compositions, which seem to be influenced by distinct processing skills. 
References

Babayiğit, S., \& Stainthorp, R. (2007). Preliterate Phonological Awareness and Early Literacy Skills in Turkish. Journal of Research in Reading, 30(4), 394-413.

Barnett, A., Stainthorp, R., Henderson, S., \& Scheib, B. (2006). Handwriting Policy and Practice in English Primary Schools: An Exploratory Study (Issues in Practices). Institute of Education.

Bereiter, C. (1980). Development in Writing. In L. W. Gregg \& E. R. Steinberg (Eds.), Cognitive Processes in Writing (Vol. 4, pp. 73-93). Hillsdale, New Jersey: Lawrence Erlbaum Association.

Berko, J. (1958). The Child's Learning of English Morphology. Word, 14, 150-177.

Berninger, V. W. (1996). Multiple Constraints and Shared Subsystems in Writing Acquisition. In V. W. Berninger (Ed.), Reading and Writing Acquisition. A Developmental Neuropsychological Approach (Vol. 6, pp. 129-152). Oxford: Westview Press.

Berninger, V. W. (1999). Coordinating Transcription and Text Generation in Working Memory During Composing: Automatic and Constructive Processes. Learning Disability Quarterly, 22(2), 99-112.

Berninger, V. W., Vaughan, K., Abbot, R., Abbot, S., Rogan, L., Brooks, A., et al. (1997). Treatment of Handwriting Problems in Beginning Writers: Transfer from Handwriting to Composition. Journal of Educational Psychology, 89(4), 652- 666.

Berninger, V. W., Yates, C., Cartwright, A., Rutberg, J., Remy, E., \& Abbot, R. (1992). LowerLevel Developmental Skills in Beginning Writing. Reading \& Writing: An Interdisciplinary Journal 4, 257-280.

Bowey, J. A. (2005). Grammatical Sensitivity: Its Origins and Potential Contribution to Early Word Reading Skill. Journal of Experimental Child Psychology, 90, 318-343.

Bruce, D. J. (1964). The Analysis of Word Sounds by Young Children. British Journal of Educational Psychology, 34, 158-169.

Bryant, P., \& Nunes, T. (2004). Morphology and Spelling. In T. Nunes \& P. Bryant (Eds.), Handbook of Literacy (Vol. A5, pp. 91-118). Dordrecht, Netherlands: Kluwer Academic Publishers.

Caravolas, M., Hulme, C., \& Snowling, M. (2001). The Foundations of Spelling Ability: Evidence from a 3-Year Longitudinal Study. Journal of Memory and Language, 45, 751774.

Carlisle, J. F. (1995). Morphological Awareness and Early Reading Ability. In L. B. Feldman (Ed.), Morphological Aspects of Language Processing (Vol. 8, pp. 189-209). Hove, UK.: Lawrence Erlbaum Associates.

Carlisle, J. F. (2000). Awareness of the Structure and Meaning of Morphologically Complex Words: Impact on Reading. Reading and Writing: An Interdisciplinary Journal, 12, 169190.

Carlisle, J. F., \& Nomanbhoy, D. M. (1993). Phonological and Morphological Awareness in the First Graders. Applied Psycholinguistics, 14, 177-195.

Connelly, V., Dockrell, J. E., \& Barnett, J. (2005). The Slow Handwriting of Undergraduate Students Constrains Overall Performance in Exam Essays. Educational Psychology, 25(1), 99 - 107.

Cragg, L., \& Nation, J. K. (2006). Exploring Written Narrative in Children with Poor Reading Comprehension. Educational Psychology, 26(1), 55-72. 
Daneman, M., \& Carpenter, P. A. (1980). Individual Differences in Working Memory and Reading. Journal of Verbal Learning and Verbal Behaviour, 19, 450-466.

de Jong, P. F., \& van der Leij, A. (1999). Specific Contributions of Phonological Abilities to Early Reading Acquisition: Results from a Dutch Latent Variable Longitudinal Study. Journal of Educational Psychology, 91(3), 450-476.

Defior, S., Alegria, J., Titos, R., \& Martos, F. (2007). Using Morphology When Spelling in a Shallow Orthographic System: The Case of Spanish. Cognitive Development.

Dufva, M., Niemi, P., \& Voeten, M. J. M. (2001). The Role of Phonological Memory, Word Recognition, and Comprehension Skills in Reading Development: From Preschool to Grade 2. Reading and Writing: An Interdisciplinary Journal, 14, 91-117.

Durgunoğlu, A. (2003). Recognising Morphologically Complex Words in Turkish. In E. Assink \& D. Sandra (Eds.), Reading Complex Words: Cross-Language Studies (Vol. 4, pp. 8192). Netherlands: Kluwer Academic Publishers.

Ekmekçi, F. Ö. (1986). The Significance of Word Order in the Acquisition of Turkish. In D. I. Slobin \& K. Zimmer (Eds.), Studies in Turkish Linguistics (pp. 265-273). Amsterdam: John Benjamins.

Fey, E. D., Catts, H., Proctor-williams, K., Toblin, J. B., \& Zhang, X. (2004). Oral and Written Story Composition Skills of Children with Language Impairment. Journal of Speech, Language, and Hearing Research, 47, 1301-1318.

Flower, L. S., \& Hayes, J. R. (1980). The Dynamics of Composing: Making Plans and Juggling Constraints. In L. W. Gregg \& E. R. Steinberg (Eds.), Cognitive Processes in Writing (Vol. 2, pp. 31-50). Hillsdale, New Jersey: LEA.

Graham, S. (1999a). Handwriting and Spelling Instruction for Students with Learning Disabilities: A Review. Learning Disability Quarterly, 22(2), 78-98.

Graham, S. (1999b). The Role of Text Production Skills in Writing Development: A Special Issue: I. Learning Disability Quarterly, 22(2), 75-77.

Graham, S., Berninger, V. W., Abbot, R. D., Abbot, S. P., \& Whitaker, D. (1997). Role of Mechanics in Composing of Elementary School Students: A New Methodological Approach. Journal of Educational Psychology, 89(1), 170-182.

Graham, S., \& Harris, K. R. (2000). Writing Development : Introduction to the Special Issue. Educational Psychologist, 35(1), 1.

Griffin, T. M., Hemphill, L., Camp, L., \& Wolf, D. P. (2004). Oral Discourse in the Preschool Years and Later Literacy Skills. First Language, 24(2), 123-147.

Joshi, R. M., \& Aaron, P. G. (Eds.). (2006). Handbook of Orthography and Literacy. London: Lawrence Erlbaum Associates.

Juel, C. (1988). Learning to Read and Write : A Longitudinal Study of 54 Children from First through Fourth Grades. Journal of Educational Psychology, 80(4), 437-447.

Juel, C., Griffith, P. L., \& Gough, P. B. (1986). Acquisition of Literacy: A Longitudinal Study of Children in First and Second Grade. Journal of Educational Psychology, 78(4), 243255.

Juul, H., \& Elbro, C. (2004). The Links between Grammar and Spelling: A Cognitive Hurdle in Deep Orthographies? Reading and Writing: An Interdisciplinary Journal, 17, 915-942.

Kellogg, R. T. (1996). A Model of Working Memory in Writing. In M. C. Levy \& S. Ransdell (Eds.), The Science of Writing: Theories, Methods, Individual Differences and Applications (Vol. 3, pp. 57-71). New Jersey: LEA. 
Kintsch, W. (1998). Comprehension: A Paradigm for Cognition. New York Cambridge University Press.

Landerl, K., \& Wimmer, H. (2008). Development of Word Reading Fluency and Spelling in a Consistent Orthography: An 8-Year Follow-Up. Journal of Educational Psychology, 100(1), 150-161.

Lehtonen, A., \& Bryant, E. P. (2005). Active Players or Just Passive Bystanders? The Role of Morphemes in Spelling Development in a Transparent Orthography. Applied Psycholinguistics, 26, 137-155.

Lewis, G. L. (1967). Turkish Grammar. Oxford: Oxford University Press.

Lyytinen, H., Erskine, J. M., Tolvanen, A., Torppaa, M., Poikkeus, A.-M., \& Lyytinen, P. (2006). Trajectories of Reading Development: A Follow-up from Birth to School Age of Children with and without Risk for Dyslexia. Merrill-Palmer Quarterly, 52(3), 514-546.

Mackie, C., \& Dockrell, J. E. (2004). The Nature of Written Language Deficits in Children with Sli. Journal of Speech, Language, and Hearing Research, 47, 1469-1483.

Maki, H. S., Voeten, M. M., Vauras, M. M. S., \& Poskiparta, E. H. (2001). Predicting Writing Skill Development with Word Recognition and Preschool Readiness Skills. Reading and Writing: An Interdisciplinary Journal, 14, 643-672.

McCutchen, D. (2000). Knowledge, Processing, and Working Memory: Implications for a Theory of Writing. Educational Psychologist, 35(1), 13-23.

McCutchen, D., Covill, A., Hoyne, S. H., \& Mildes, K. (1994). Individual Differences in Writing: Implications of Translating Fluency. Journal of Educational Psychology, 86(2), 256-266.

Muter, V., Hulme, C., Snowling, M., \& Stevenson, J. (2004). Phonemes, Rimes, Vocabulary, and Grammatical Skills as Foundations of Early Reading Development: Evidence from a Longitudinal Study. Developmental Psychology, 40(5), 665-681.

Muter, V., \& Snowling, M. (1997). Grammar and Phonology Predict Spelling in Middle Childhood. Reading and Writing: An Interdisciplinary Journal, 9, 407-425.

Nikolopoulos, D., Goulandris, N., Hulme, C., \& Snowling, M. (2006). The Cognitive Bases of Learning to Read and Spell in Greek: Evidence from a Longitudinal Study. Journal of Experimental Child Psychology, 94, 1-17.

Nunes, T., Bryant, E. P., \& Bindman, M. (1997). Learning to Spell Regular and Irregular Verbs. Reading and Writing: An Interdisciplinary Journal, 9, 427-449.

Öney, B., \& Durgunoglu, A. (1997). Beginning to Read in Turkish: A Phonologically Transparent Orthography. Applied Psycholinguistics, 18, 1-15.

Patel, T. K., Snowling, M., \& de Jong, P. (2004). A Cross-Linguistic Comparison of Children Learning to Read in English and Dutch. Journal of Educational Psychology, 96(4), 785797.

Pattison, H. M., \& Collier, J. (1992). Methodological Issues in the Investigation of Spelling and Spelling Development. In C. M. Sterling \& C. Robson (Eds.), (Vol. 6, pp. 100-113).

Powell, D., Stainthorp, R., Stuart, M., Garwood, H., \& Quinlan, P. (2007). An Experimental Comparison between Rival Theories of Rapid Automatized Naming Performance and Its Relationship to Reading. Journal of Experimental Child Psychology, 98(1), 46-68.

Raven, J. C. (1967). Standard Progressive Matrices. Oxford: Oxford Psychologists Press.

Rispen, J. E., McBride-Chang, C., \& Reitsma, P. (2008). Morphological Awareness and Early and Advanced Word Recognition and Spelling in Dutch. Reading \& Writing: An Interdisciplinary Journal, 21, 587-607. 
Savage, R., \& Frederickson, N. (2005). Evidence of a Highly Specific Relationship between Rapid Automatic Naming of Digits and Text-Reading Speed. Brain and Language, 93, 152-159.

Savasir, L., \& Sahin, N. (1995). Wechsler Çocuklar Için Zeka Ölçegi (Wisc-R). Ankara, Turkey: Türk Psikologlar Dernegi Yayini.

Senechal, M., Basque, M., \& Leclaire, T. (2006). Morphological Knowledge as Revealed in Children's Spelling Accuracy and Reports of Spelling Strategies. Journal of Experimental Child Psychology, 95, 231-254.

Silven, M., Poskiparta, E., Niemi, P., \& Voeten, M. J. M. (2007). Precursors of Reading Skills from Infancy to First Grade in Finnish: Continuity and Change in a Highly Inflected Language. Journal of Educational Psychology, 99(3), 516-531.

Singson, M., Mahony, D., \& Mann, V. (2000). The Relation between Reading Ability and Morphological Skills: Evidence from Derivational Suffixes. Reading and Writing: An Interdisciplinary Journal, 12, 219-252.

Swanson, H. L., \& Berninger, V. W. (1996). Individual Differences in Children's Working Memory and Writing Skills. Journal of Experimental Child Psychology, 63, 358-385.

Tabachnick, B. G., \& Fidell, L. S. (2001). Using Multivariate Statistics (4th ed.). London: Allyn and Bacon.

Titos, R., Defior, S., Alegria, J., \& Martos, F. J. (2003). The Use of Morphological Resources in Spanish Orthography: The Case of the Verb. In R. M. Joshi, C. K. Leong \& B. L. J. Kaczmarek (Eds.), Literacy Acquisition: The Role of Phonology, Morpholgy and Orthography (Vol. II, pp. 113-118). Oxford: IOS Press.

Treiman, R., \& Kessler, B. (2005). Writing Systems and Spelling Development. In M. Snowling \& C. Hulme (Eds.), The Science of Reading (Vol. 7, pp. 120- 134). Oxford: Blackwell.

van Bon, W. H. J., \& van Leeuwe, J. F. J. (2003). Assessing Phonemic Awareness in Kindergarten: The Case for the Phoneme Recognition Task. Applied Psycholinguistics, 24, 195-219.

Wagner, R. K., Torgesen, J. K., Rashotte, C. A., Hecht, S. A., Barker, T. A., Burgess, S. R., et al. (1997). Changing Relations between Phonological Processing Abilities and Word-Level Reading as Children Develop from Beginning to Skilled Readers: A 5-Year Longitudinal Study. Developmental Psychology, 33(3), 468-479.

Wimmer, H., \& Mayringer, H. (2002). Dysfluent Reading in the Absence of Spelling Difficulties: A Specific Disability in Regular Orthography. Journal of Educational Psychology, 94(2), 272-277.

Wolf, M., Bowers, P. G., \& Biddle, K. (2000). Naming-Speed Processes, Timing, and Reading: A Conceptual Review. Journal of Learning Disabilities, 33(4), 387-407. 


\section{Appendix A}

\section{Examples from the Phonological and Grammatical Awareness Measures}

\section{Phonological Awareness Measures}

\section{Syllable Deletion}

Words

Kedi (cat)

Kalem (pencil)

Pencere (window)

\section{Nonwords}

Taska

Dezmene

Sormato
To be deleted syllable

Di

$\mathrm{Ka}$

$\mathrm{Ce}$

Tas

Dez

Ma
Answer

$\mathrm{Ke}$

Lem

Penre

\section{Phoneme deletion}

\section{Words}

Top (ball)

$\mathrm{P}$

To

Kuş (bird)

K

Uş

Tost (toast)

S

Tot

Nonwords

Gede

G

Ede

Delp

L

Dep

Pendir

$\mathrm{N}$

Pedir 


\section{Grammatical Awareness Measures}

\section{Judgment}

Inaccurate inflectional suffix

KEV-e ormanlarda yaşarlar.

Accurate inflectional suffix

KEV-in uzun kulakları vardır.

\section{English Translations}

To KEV lives in the forests

KEV has long ears.

\section{Judgment/Correction}

Inaccurate inflectional suffix

BEV-i yemek verdim.

I gave food the BEV.

Accurate inflectional suffix

BEV-e yemek verdim.

I gave food to the BEV.

\section{Syntactic Awareness}

a) Inaccurate word order

Kardeşim üç var.

Accurate word order

Üç kardeşim var.

I have three siblings.

b) Inaccurate word order

Bütün çalıştı gün.

Accurate word order

Bütün gün çalıştı.

(S/he) worked whole day. 


\section{Appendix B}

Scoring the Composition-Writing Structure

a) Appropriate sequencing:

0) Incorrect

1) Correct

b) Sentence Structure

0) Majority of sentences are incomplete, fragments or run -ons.

1) One or two incomplete sentences. Majority of sentences are complete.

2) Every sentence is a complete sentence.

c) Sentence variety

0) Repeating

1) Varied

d) Complexity of sentence structure

0) All simple sentences.

1) One sentence with one subordinate clause.

2) Two or more sentences with one subordinate clause in each.

3) One sentence with two or more subordinate clauses, and one or more sentences with one subordinate clause in each.

4) Two or more sentences with multiple subordinate clauses in each.

e) Linking expressions (and, or but, while, then, before, suddenly)

0) No linking expressions

1) Two or less linking expressions of the same kind. E.g., if only one type of linking word such as AND is used 
2) Three or four linking expressions. At least one is a word other then AND.

3) More than five linking expressions. At least three is a word other than AND.

e) Consistency of tense

0) Switching of tense

1) Tense is appropriate and consistent

f) Grammar

0) Very poor grammar that makes interpretation difficult

1) Some grammar errors that sometimes interfere with meaning or interpretation

2) A few errors but do not detract the overall quality of expression

3) Error free 
Table 1

Measures and Descriptive Statistics

\begin{tabular}{|c|c|c|c|c|}
\hline \multirow[b]{2}{*}{ Measure/ Maximum possible score } & \multicolumn{2}{|l|}{ Grade $1(N=57)$} & \multicolumn{2}{|c|}{ Grade $2(N=48)$} \\
\hline & $\mathrm{M}(S D)$ & Reliability & $\mathrm{M}(S D)$ & Reliability \\
\hline 1. Raven's Standard Progressive Matrices / $36^{\mathrm{a}}$ & $13.70(3.40)$ & $.95^{\mathrm{d}}$ & & \\
\hline 2. Block design/ $69^{a}$ & $8.06(5.91)$ & $.98^{\mathrm{d}}$ & & \\
\hline 3. Vocabulary / $68^{\mathrm{a}}$ & $12.88(4.78)$ & $.96^{\mathrm{d}}$ & & \\
\hline 4. Forward Digit- span / 14 & $3.35(1.17)$ & $.98^{\mathrm{d}}$ & & \\
\hline 5. RAN/ na & $50.81(10.82)$ & $.98^{\mathrm{e}}$ & & \\
\hline 6. Working memory / 9 & $2.45(1.43)$ & $.95^{\mathrm{e}}$ & & \\
\hline 7. Syllable deletion / 21 & $10.09(5.53)$ & $.87^{\mathrm{f}}$ & & \\
\hline 8. Phoneme deletion /18 & $5.93(5.06)$ & $.79^{\mathrm{f}}$ & & \\
\hline 9. Morphology awareness /36 & $22.87(5.43)$ & $.78^{\mathrm{f}}$ & & \\
\hline 10. Syntactic awareness/ 20 & $7.60(3.78)$ & $.80^{\mathrm{f}}$ & & \\
\hline 11. Word reading/na ${ }^{b}$ & $13.33(6.99)$ & & $25.56(8.18)$ & $.75^{\mathrm{g}}$ \\
\hline 12. Nonword reading/ na ${ }^{\mathrm{b}}$ & $12.85(6.52)$ & & $20.88(6.06)$ & $.74^{\mathrm{g}}$ \\
\hline
\end{tabular}




\begin{tabular}{|c|c|c|c|c|}
\hline \multirow[b]{2}{*}{ Measure/ Maximum possible score } & \multicolumn{2}{|c|}{ Grade $1(N=57)$} & \multicolumn{2}{|c|}{ Grade $2(N=48)$} \\
\hline & $\mathrm{M}(S D)$ & Reliability & $\mathrm{M}(S D)$ & Reliability \\
\hline 13. Agglutinated word reading/ na ${ }^{b}$ & $10.44(4.89)$ & & $18.22(5.48)$ & $.75^{\mathrm{g}}$ \\
\hline 14. Text reading accuracy/ 61 & $58.81(2.36)$ & & $59.46(1.43)$ & $.30^{\mathrm{g}}$ \\
\hline 15. Text reading speed/na ${ }^{b}$ & $32.40(12.57)$ & & $52.12(15.59)$ & $.84^{\mathrm{g}}$ \\
\hline 16. Spelling- Single word / 17 & $7.70(3.60)$ & $.81^{\mathrm{f}}$ & $12.57(2.46)$ & $.79^{\mathrm{f}}$ \\
\hline 17. Spelling-Sentence /9 & $1.80(1.83)$ & $.70^{\mathrm{f}}$ & $4.60(1.96)$ & $.73^{\mathrm{f}}$ \\
\hline 18. Handwriting speed/na ${ }^{c}$ & $4.49(1.56)$ & & $10.65(2.07)$ & $.71^{\mathrm{g}}$ \\
\hline 19. Composition writing- spelling error rate/100 & & & $.10(.08)$ & $.99^{\mathrm{h}}$ \\
\hline 20. Composition writing - fluency / na ${ }^{c}$ & & & $7.62(1.74)$ & $.98^{\mathrm{h}}$ \\
\hline 21. Composition writing - content/ 9 & & & $4.32(1.38)$ & $.83^{\mathrm{h}}$ \\
\hline 22. Composition writing - structure/ 15 & & & $7.81(2.48)$ & $.74^{\mathrm{h}}$ \\
\hline
\end{tabular}

Note. $/ \mathrm{na}=$ Not applicable/available. ${ }^{\mathrm{a}}$ Raw scores were used as there were no norms for Northern Cyprus. ${ }^{\mathrm{b}}$ Scored as the number of correct words per minute; ${ }^{\mathrm{c}}$ Total number of words written per minute; ${ }^{\mathrm{d}}$ Reported in the test manual; ${ }^{\mathrm{e}}$ Split-half reliability; ${ }^{\mathrm{f}}$ Cronbach's alpha; ${ }^{\mathrm{g}}$ Test-retest reliability after 11 months; ${ }^{\mathrm{h}}$ Inter-rater reliability. 
Table 2

Correlations between the Measures at Grade 1

\begin{tabular}{|c|c|c|c|c|c|c|c|c|c|c|c|c|c|c|c|c|c|}
\hline Measures & 1 & 2 & 3 & 4 & 5 & 6 & 7 & 8 & 9 & 10 & 11 & 12 & 13 & 14 & 15 & 16 & 17 \\
\hline 1. RSPM & - & & & & & & & & & & & & & & & & \\
\hline 2. $\mathrm{BD}$ & $.54^{*}$ & - & & & & & & & & & & & & & & & \\
\hline 3. VOC & .17 & .18 & - & & & & & & & & & & & & & & \\
\hline 4. STM & $.39 *$ & $.39 *$ & .05 & - & & & & & & & & & & & & & \\
\hline 5. WM & .15 & .18 & $.36^{*}$ & .18 & - & & & & & & & & & & & & \\
\hline 6. SDA & $.40^{*}$ & $.41 *$ & .25 & $.50 *$ & $.41^{*}$ & - & & & & & & & & & & & \\
\hline 7. PDA & $.56^{*}$ & $.50 *$ & .22 & $.55^{*}$ & $.32 *$ & $.70 *$ & - & & & & & & & & & & \\
\hline 8. RAN & -.08 & -.13 & -.11 & -.02 & -.13 & $-.39 *$ & -.20 & & & & & & & & & & \\
\hline 9. MA & $.29 *$ & $.36^{*}$ & .23 & $.46^{*}$ & .16 & $.32 *$ & $.31 *$ & -.17 & - & & & & & & & & \\
\hline 10. SA & $.56^{*}$ & $.61^{*}$ & $.35^{*}$ & $.45^{*}$ & $.40^{*}$ & $.53 *$ & $.53 *$ & -.17 & $.57 *$ & - & & & & & & & \\
\hline 11. WR & .24 & .26 & .13 & $.49 *$ & .24 & $.50 *$ & $.45^{*}$ & $-57 *$ & $.51 *$ & .38 & - & & & & & & \\
\hline 12. NWR & .16 & .17 & .08 & $.43^{*}$ & $.29^{*}$ & $.48 *$ & $.45^{*}$ & $-.60 *$ & $.40^{*}$ & $.29 *$ & $.92^{*}$ & - & & & & & \\
\hline 13. AWR & .24 & $.33^{*}$ & .14 & $.45^{*}$ & $.29 *$ & $.57 *$ & $.46^{*}$ & $-.66^{*}$ & $.36 *$ & $.40 *$ & $.88^{*}$ & $.85^{*}$ & - & & & & \\
\hline
\end{tabular}




\begin{tabular}{llllllllllllllllllll}
\hline Measures & 1 & 2 & 3 & 4 & 5 & 6 & 7 & 8 & 9 & 10 & 11 & 12 & 13 & 14 & 15 & 16 & 17 \\
\hline $14 . \mathrm{TRS}$ & .10 & .17 & .05 & $.35^{*}$ & .14 & $.40^{*}$ & .26 & $.70^{*}$ & .23 & .22 & $.81^{*}$ & $.79^{*}$ & $.78^{*}$ & - \\
$15 . \mathrm{SpW}$ & .17 & $.29^{*}$ & .17 & $.41^{*}$ & .16 & $.51^{*}$ & $.46^{*}$ & -.13 & $.61^{*}$ & $.50^{*}$ & $.64^{*}$ & $.57^{*}$ & $.62^{*}$ & $.51^{*}$ & - \\
$16 . \mathrm{SpS}$ & .15 & $.43^{*}$ & $.33^{*}$ & $.44^{*}$ & .09 & $.38^{*}$ & $.34^{*}$ & -.15 & $.60^{*}$ & $.55^{*}$ & $.56^{*}$ & $.45^{*}$ & $.50^{*}$ & $.34^{*}$ & $.68^{*}$ & - & & \\
$17 . \mathrm{HWS}$ & .12 & .08 & -.05 & $.40^{*}$ & $.32^{*}$ & .05 & .18 & $-.42^{*}$ & $.29 *$ & $.39^{*}$ & $.39 *$ & $.36^{*}$ & $.39^{*}$ & .26 & $.55^{*}$ & $.46^{*}$ & -
\end{tabular}

Note. RSPM= Raven's standard progressive matrices; $\mathrm{BD}=$ Block design; VOC=Vocabulary; STM=Short-term memory;

WM=Working memory; SDA=Syllable deletion-accuracy; PDA= Phoneme deletion- accuracy; RAN=Rapid automatised naming;

MA=Morphological awareness; $\mathrm{SA}=$ Syntactic awareness; WR=Word reading; NWR=Nonword reading; AWR=Agglutinated word reading; TRS=Text reading speed; SpW=Spelling -word; SpS=Spelling -sentence; HWS=Handwriting speed.

$* p<.05$. 
Table 3

Correlations between the Measures at Grade 2

\begin{tabular}{|c|c|c|c|c|c|c|c|c|c|c|c|}
\hline Measures & 1 & 2 & 3 & 4 & 5 & 6 & 7 & 8 & 9 & 10 & 11 \\
\hline 1. WR & - & & & & & & & & & & \\
\hline 2. NWR & $.87 *$ & - & & & & & & & & & \\
\hline 3. AWR & $.79 *$ & $.83^{*}$ & - & & & & & & & & \\
\hline 4. TRS & $.88^{*}$ & $.81^{*}$ & $.78 *$ & - & & & & & & & \\
\hline 5. $\mathrm{SpW}$ & .19 & .09 & -.09 & .15 & - & & & & & & \\
\hline 6. $\mathrm{SpS}$ & $.34 *$ & .28 & .07 & $.32 *$ & $.51 *$ & - & & & & & \\
\hline 7. CWE & $-.38 *$ & -.26 & -.15 & -.34 & $-.44 *$ & $-.54 *$ & - & & & & \\
\hline 8. CWF & .14 & .24 & -.01 & .13 & .17 & .32 & -.21 & - & & & \\
\hline 9. $\mathrm{CWC}$ & .11 & .06 & -.13 & .09 & .28 & .23 & -.07 & .20 & - & & \\
\hline 10. CWS & -.05 & .10 & & .24 & .20 & .21 & -.24 & $.34 *$ & $.59 *$ & - & \\
\hline 11. HWS & .19 & .18 & .13 & .11 & .18 & .25 & $-.35^{*}$ & $.63^{*}$ & .08 & .12 & - \\
\hline
\end{tabular}

Note. $\mathrm{WR}=$ Word reading; $\mathrm{NWR}=$ Nonword reading; AWR=Agglutinated word reading; $\mathrm{TRS}=$ Text reading speed; SpW=Spelling -

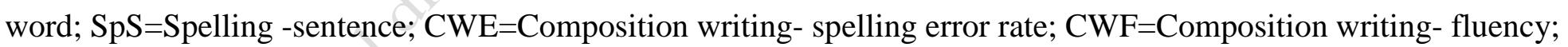

$\mathrm{CWC}=$ Composition writing- content $\mathrm{CWS}=$ Composition writing- structure; HWS $=$ Handwriting speed. 
$* p<.05$. 
Table 4

Longitudinal Correlations between the Grade 1 and Grade 2 Measures

\begin{tabular}{|c|c|c|c|c|c|c|c|c|c|c|c|}
\hline \multirow{2}{*}{$\begin{array}{l}\text { Grade } 1 \\
\text { Measures }\end{array}$} & \multicolumn{11}{|c|}{ Grade 2 measures } \\
\hline & WR & NWR & AWR & TRS & SpW & $\mathrm{SpS}$ & CWE & CWF & CWC & CWS & HWS \\
\hline 1. RSPM & .11 & .07 & -.02 & -.04 & .23 & .22 & -.14 & .08 & .22 & .17 & .17 \\
\hline 2. $\mathrm{BD}$ & .22 & .14 & -.02 & .09 & .20 & .23 & -.10 & .11 & .23 & .20 & .31 \\
\hline 3. IQ & .21 & .14 & -.03 & .07 & .21 & .20 & -.14 & .12 & .14 & .23 & .25 \\
\hline 4. VOC & .03 & -.00 & -.12 & .04 & .14 & .07 & .14 & .08 & .53 & .09 & .13 \\
\hline 5. STM & $.40 *$ & $.33^{*}$ & $.28 *$ & $.40 *$ & $.35^{*}$ & $.37 *$ & -.16 & .25 & .16 & .27 & $.39 *$ \\
\hline 6. WM & .15 & .15 & .16 & .25 & .13 & .23 & .06 & .05 & $.55^{*}$ & -.04 & .02 \\
\hline 7. SDA & $.39 *$ & $.33 *$ & $.31 *$ & $.38 *$ & $.52 *$ & .25 & -20 & .02 & .25 & .22 & $.32 *$ \\
\hline 8. PDA & $.34 *$ & .25 & $.30 *$ & .23 & $.31 *$ & .24 & -.24 & .14 & .18 & .16 & $.43^{*}$ \\
\hline 9. PA & $.35^{*}$ & $.28 *$ & $.30 *$ & $.29 *$ & $.42 *$ & .23 & -.20 & .09 & .17 & .17 & $.39 *$ \\
\hline 10. RAN & $-.73 *$ & $-.67 *$ & $-.56^{*}$ & $-.64 *$ & -.22 & -.25 & .20 & -.04 & -.15 & .07 & $-.38 *$ \\
\hline 11. MA & .22 & .04 & -.04 & $.28 *$ & $.45^{*}$ & $.53 *$ & $-.35^{*}$ & .11 & .17 & .10 & $.31 *$ \\
\hline 12. SA & .18 & .08 & .02 & .19 & $.42 *$ & $.40 *$ & -.15 & .18 & $.34 *$ & .27 & $.33 *$ \\
\hline 13. GA & .20 & .06 & -.02 & .22 & $.59 *$ & $.49 *$ & $-.29 *$ & .20 & .20 & .20 & $.32 *$ \\
\hline
\end{tabular}




\begin{tabular}{|c|c|c|c|c|c|c|c|c|c|c|c|}
\hline \multirow{2}{*}{$\begin{array}{l}\text { Grade } 1 \\
\text { Measures }\end{array}$} & \multicolumn{11}{|c|}{ Grade 2 measures } \\
\hline & WR & NWR & AWR & TRS & SpW & $\mathrm{SpS}$ & $\mathrm{CWE}$ & $\mathrm{CWF}$ & $\mathrm{CWC}$ & CWS & HWS \\
\hline 14. WR & $.75^{*}$ & $.72 *$ & $.63^{*}$ & $.78^{*}$ & $.36^{*}$ & $.41 *$ & $-28 *$ & .10 & .21 & .17 & .24 \\
\hline 15. NWR & $.78 *$ & $.74 *$ & $.72 *$ & $.77 *$ & $.29 *$ & $.38 *$ & $-.29 *$ & .06 & .18 & .14 & .17 \\
\hline 16. AWR & $.78 *$ & $.75^{*}$ & $.64 *$ & $.78 *$ & $.35^{*}$ & $.43 *$ & -.25 & .16 & .16 & $.28 *$ & .16 \\
\hline 17. TRS & $.87 *$ & $.83^{*}$ & $.71 *$ & $.84 *$ & .24 & $.38 *$ & $-.40 *$ & .00 & .16 & .23 & .17 \\
\hline 18. SpW & $.44^{*}$ & $.32 *$ & .25 & $.54 *$ & $.57 *$ & $.64 *$ & $-.50 *$ & .11 & .12 & $.29 *$ & .18 \\
\hline 19. $\mathrm{SpS}$ & $.39 *$ & $.30 *$ & .11 & $.38 *$ & $.48^{*}$ & $.54 *$ & -.20 & .20 & .24 & .22 & $.34 *$ \\
\hline 20. HWS & $.42 *$ & $.46^{*}$ & .24 & $.44 *$ & .24 & $.55^{*}$ & -.19 & $.47 *$ & .23 & .21 & $.71^{*}$ \\
\hline
\end{tabular}

Note. RSPM= Raven's standard progressive matrices; $\mathrm{BD}=$ Block design; IQ=Composite measure of IQ; VOC= Vocabulary;

STM=Short-term memory; WM= Working memory; SDA=Syllable deletion-accuracy; PDA=Phoneme deletion- accuracy;

$\mathrm{PA}=$ Composite measure of phonological awareness; $\mathrm{RAN}=$ Rapid automatised naming; $\mathrm{MA}=\mathrm{Morphological}$ awareness; $\mathrm{SA}=$

Syntactic awareness; GA=Composite measure of grammatical awareness; WR=Word reading; NWR=Nonword reading; $A W R=$

Agglutinated word reading; TRS= Text reading speed; $\mathrm{SpW}=$ Spelling -word; $\mathrm{SpS}=$ Spelling -sentence; HWS= Handwriting speed;

$\mathrm{CWE}=$ Composition writing- spelling error rate; $\mathrm{CWF}=\mathrm{Composition}$ writing- fluency; $\mathrm{CWC}=\mathrm{Composition}$ writing- content; $\mathrm{CWS}=$

Composition writing- structure.

$* p<.05$. 
Table 5

Hierarchical Regression Analysis: Grade 1 Predictors of Reading Skills at Grade 2

\begin{tabular}{|c|c|c|c|c|c|c|c|c|c|}
\hline \multirow[b]{3}{*}{ Step } & \multirow[b]{3}{*}{ Grade 1 Measures } & \multicolumn{8}{|c|}{ Reading skills at Grade 2} \\
\hline & & \multicolumn{2}{|c|}{ Word Reading } & \multicolumn{2}{|c|}{ Nonword reading } & \multicolumn{2}{|c|}{$\begin{array}{l}\text { Agglutinated word } \\
\text { reading }\end{array}$} & \multicolumn{2}{|c|}{ Text reading speed } \\
\hline & & $\mathrm{R}^{2}$ & $\Delta \mathrm{R}^{2}$ & $\mathrm{R}^{2}$ & $\Delta \mathrm{R}^{2}$ & $\mathrm{R}^{2}$ & $\Delta \mathrm{R}^{2}$ & $\mathrm{R}^{2}$ & $\Delta \mathrm{R}^{2}$ \\
\hline \multicolumn{10}{|c|}{ Model 1} \\
\hline 1 & Autoregressor & & $.57 * * *$ & & $.55^{* * * *}$ & & $.41 * * *$ & & $.70 * * *$ \\
\hline 2 & STM & .57 & .00 & .55 & .00 & .41 & .00 & .70 & .01 \\
\hline 2 & Phonological awareness & .57 & $.00 \curvearrowright$ & .55 & .00 & .41 & .00 & .70 & .00 \\
\hline 2 & RAN & .76 & $.11 * *$ & .65 & $.07 *$ & .43 & $.04 *$ & .70 & .01 \\
\hline \multicolumn{10}{|c|}{ Model 2} \\
\hline 1 & STM & & $.16^{* *}$ & & $.11 *$ & & $.08 *$ & & $.16^{* *}$ \\
\hline 2 & Phonological awareness & .22 & $.06^{*}$ & .14 & .03 & .14 & $.06^{*}$ & .19 & .02 \\
\hline 2 & RAN & .61 & $.50 * * *$ & .52 & $.42 * * *$ & .36 & $.30 * * *$ & .50 & $.38 * * *$ \\
\hline 1 & STM, Phonological awareness & & $.20 *$ & & $.13^{*}$ & & $.13^{*}$ & & $.18^{*}$ \\
\hline 2 & RAN & .62 & $.42 * * *$ & .52 & $.39 * * *$ & .37 & $.24 * *$ & .50 & $.32 * * *$ \\
\hline
\end{tabular}


Note. $\Delta \mathrm{R}^{2}=$ Change in explained variance; $\mathrm{RAN}=$ Rapid automatized naming.

$* p<.05 . * * p<.01 . * * * p<.001$. 
Table 6

Hierarchical Regression Analysis: Grade 1 Predictors of Spelling Skills at Grade 2

\begin{tabular}{|c|c|c|c|c|c|c|c|}
\hline \multirow[b]{3}{*}{ Step } & \multirow[b]{3}{*}{ Grade 1 Measures } & \multicolumn{6}{|c|}{ Spelling skills at Grade 2} \\
\hline & & \multicolumn{2}{|c|}{ Spelling - word } & \multicolumn{2}{|c|}{ Spelling- sentence } & \multicolumn{2}{|c|}{ Spelling error rate } \\
\hline & & $\mathrm{R}^{2}$ & $\Delta \mathrm{R}^{2}$ & $\mathrm{R}^{2}$ & $\Delta \mathrm{R}^{2}$ & $\mathrm{R}^{2}$ & $\Delta \mathrm{R}^{2}$ \\
\hline \multicolumn{8}{|c|}{ Model 1} \\
\hline 1 & Autoregressor & & $.35 * * *$ & & $.29 * * *$ & & $.22 * * \mathrm{a}$ \\
\hline 2 & STM & .35 & .01 & .32 & .02 & .23 & .00 \\
\hline 2 & Phonological awareness & .39 & $.04, p=.091$ & .30 & .00 & .22 & .00 \\
\hline 2 & Grammatical awareness & .42 & $.09 *$ & .32 & .03 & .24 & .00 \\
\hline \multicolumn{8}{|c|}{ Model 2} \\
\hline 1 & STM & & $.10 *$ & & $.14 * *$ & & .03 \\
\hline 2 & Phonological awareness & .24 & $.14 * *$ & .15 & .01 & .07 & .04 \\
\hline 3 & Grammatical awareness & .41 & $.17 * *$ & .26 & $.13^{*}$ & .10 & .04 \\
\hline 2 & Grammatical awareness & .35 & $.27 * * *$ & .25 & $.14^{* *}$ & .09 & .07 \\
\hline 3 & Phonological awareness & .41 & $.05, p=.067$ & .26 & .00 & .10 & .01 \\
\hline
\end{tabular}

Note. $\Delta \mathrm{R}^{2}=$ Change in explained variance; ${ }^{\mathrm{a}}=$ Spelling- word. 
$* p<.05 . * * p<.01 . * * * p<.001$. 
Table 7

The Longitudinal Predictors of Composition Writing-Spelling Error Rate and Composition Writing- Fluency

\begin{tabular}{llccccc}
\hline & \multicolumn{2}{l}{ Composition writing- spelling error rate } & \multicolumn{2}{c}{ Composition writing -fluency } \\
\cline { 2 - 7 } Grade 1 Measures & B & SE B & Beta & B & SE B & Beta \\
\hline Spelling- Word & -.04 & .01 & $-.52^{* *}$ & -.14 & .08 & -.29 \\
Handwriting speed & .01 & .01 & .10 & .63 & .16 & $.66^{* * *}$ \\
\hline
\end{tabular}

Note. $\mathrm{R}^{2}$ (adjusted) =.23 (.19) for composition writing- spelling error rate; $\mathrm{R}^{2}$ (adjusted) =.28 (.25) for composition writing- fluency $(p \mathrm{~s}<.01) . \mathrm{B}=\mathrm{Unnstandardized} \mathrm{beta} ; \mathrm{SE}=$ Standard error; Beta= Standardized regression coefficient.

$* p<.05 . * * p<.01 . * * * p<.001$.

Table 8

The Concurrent Predictors of Composition Writing-Spelling Error Rate and Composition Writing-Fluency

\begin{tabular}{llccccc}
\hline & \multicolumn{2}{l}{ Composition writing- spelling error rate } & \multicolumn{3}{c}{ Composition writing -fluency } \\
\cline { 2 - 7 } Grade 2 Measures & B & SE B & Beta & B & SE B & Beta \\
\hline Spelling- Word & -.03 & .01 & $-.42^{* *}$ & -.13 & .20 & -.08 \\
Handwriting speed & .00 & .01 & .07 & .48 & .10 & $.62^{* * *}$ \\
\hline
\end{tabular}


Note. $\mathrm{R}^{2}$ (adjusted) =.17(.13) for composition writing- spelling error rate; $\mathrm{R}^{2}$ (adjusted) $=.40(.37$ ) for composition writing- fluency $(p s<.05) . \mathrm{B}=$ Unstandardized beta; $\mathrm{SE}=$ Standard error; $\mathrm{Beta}=$ Standardized regression coefficient.

$* p<.05 . * * p<.01 . * * * p<.001$. 
Table 9

The Longitudinal Predictors of Composition Writing-Content and Composition Writing - Structure

\begin{tabular}{|c|c|c|c|c|c|c|}
\hline \multirow[b]{2}{*}{ Grade 1 Measures } & \multicolumn{3}{|c|}{ Composition Writing-Content } & \multicolumn{3}{|c|}{ Composition Writing-Structure } \\
\hline & $\mathrm{B}$ & SE B & Beta & B & SE B & Beta \\
\hline Spelling- Word & .10 & .17 & .10 & .17 & .22 & .18 \\
\hline Vocabulary & .35 & .14 & $.35^{*}$ & .03 & .16 & .03 \\
\hline Working Memory & .41 & .15 & $.39 * *$ & .02 & .18 & .02 \\
\hline Grammatical awareness & .02 & .18 & .02 & .07 & .22 & .07 \\
\hline
\end{tabular}

Note. $\mathrm{R}^{2}$ (adjusted) = .43 (.37), $p<.01$ for composition writing- content; $\mathrm{R}^{2}$ (adjusted) = .06 (-.05), $\mathrm{p}>.05$ for composition writingstructure. $\mathrm{B}=$ Unstandardized beta; $\mathrm{SE}=$ Standard error; Beta $=$ Standardized regression coefficient.

$* p<.05 . * * p<.01$ 
Table 10

Does Vocabulary Explain Variance in Composition Writing -Content after excluding the Choice of Vocabulary Ratings from the Overall Content Scores?

Composition Writing-Content (after excluding the choice of vocabulary)

\begin{tabular}{llll} 
Grade 1 Measures & $\mathrm{B}$ & SE B & Beta \\
\hline Spelling- Word & .12 & .14 & .16 \\
Vocabulary & .26 & .12 & $.34 *$ \\
Working Memory & .21 & .12 & .27 \\
Grammatical awareness & -.09 & .16 & -.11 \\
& & \\
Note. $\mathrm{R}^{2}($ adjusted $)=.27(.19), p<.05 . \mathrm{B}=$ Unstandardized beta; SE=Standard \\
error; Beta $=$ Standardized regression coefficient. \\
$* p<.05 . * * p<.01$.
\end{tabular}

